\title{
A Study of Polishing Feature of Ultrasonic-Assisted Vibration Method in Bamboo Charcoal
}

\author{
Hsin-Min Lee ${ }^{1}$ and Tzung-Ming Chen ${ }^{2}$ \\ ${ }^{1}$ Department of Mechanical Engineering, Army Academy, Taoyuan City, Taiwan \\ ${ }^{2}$ Department of Industrial Education and Technology, National Changhua University of Education, Changhua City, Taiwan
}

Correspondence should be addressed to Hsin-Min Lee; 1sm5762@gmail.com

Received 8 June 2017; Accepted 14 August 2017; Published 20 September 2017

Academic Editor: Hiroshi Noguchi

Copyright ( 2017 Hsin-Min Lee and Tzung-Ming Chen. This is an open access article distributed under the Creative Commons Attribution License, which permits unrestricted use, distribution, and reproduction in any medium, provided the original work is properly cited.

\begin{abstract}
Focusing on the feature of porosity in bamboo charcoal, this study applies the ultrasonic-assisted vibration method to perform surface polishing of the silicon wafer workpiece. The self-developed bamboo charcoal polishing spindle and ultrasonic- assisted vibration mechanism are attached to a single lapping machine. In the machining process, ultrasonic vibration enables the diamond slurry to smoothly pass through the microscopic holes of bamboo charcoal; the end of the bamboo charcoalis able to continue machining on the surface of the workpiece through the grasping force which exists in the microscopic holes. Under the polishing and machining parameters of ultrasonic-assisted vibration, with a diamond slurry concentration of $0.3 \%$, the experimental results show a polishing time of $20 \mathrm{~min}$, a loading of $25 \mathrm{~N}$ on the workpiece surface, a spindle speed of $1200 \mathrm{rpm}$, a vibration frequency of $30 \mathrm{kHz}$ and the original surface roughness value of $\mathrm{Ra} 0.252 \mu \mathrm{m}$ equals that of a mirror-like surface at $\mathrm{Ra} 0.017 \mu \mathrm{m}$. These research results prove that by using bamboo charcoal and ultrasonic-assisted vibration for polishing, a very good improvement can be achieved on the workpiece surface.
\end{abstract}

\section{Introduction}

Bamboo charcoal is made of Moso bamboo after heat treatment under high temperature (over $1000^{\circ} \mathrm{C}$ ); it is a material with electrical conductivity and porosity $[1,2]$. However, since many industries have to apply porous materials to their polishing processes, bamboo charcoal is in great shortage for industrial applications, which is very unfortunate. Applying chemical mechanical polishing (CMP) equipment is a common practice in industries for the planarization of silicon wafers. The main requirements of CMP treatment include a slurry, polishing pad, diamond conditioner and cleaning equipment. For these components, slurry plays an important role in removing material and ensuring good surface quality of polished silicon wafers. Polishing pads remove silicon wafer material and achieve uniformity, while diamond conditioners make use of the asperity structure produced by the conditioning of polishing pad surfaces [3]. Nevertheless, continuous polishing worsens the polishing pad. Not only is its lifecycle shortened, but it is hard to predict the right timing for pad replacement [4]. Besides, the reacting chemical is gradually consumed on a silicon wafer surface, leading to scratches on the silicon wafer produced by the thick, sticky grinding slurry and causing serious environmental problems because of the hazardous chemicals involved [5-7].

Ultrasonic vibration-assisted (UV-A) machining can be extensively applied to non-conductive or brittle workpiece materials, such as the machining of engineering ceramics. As proven by many researchers, machining via UV has positive results. $\mathrm{Li}$ et al. [8] used cerium oxide $(\mathrm{CeO} 2)$ to carry out UV dry polishing research on fused silica; Li et al's research results showed that regardless of the machining conditions, such as feed rate, spindle speed or loading, UV could enhance the material removal rate Suzuki et al. [9] used a two-axis UV polishing method to carry out ultra-precision finishing on the micro-aspheric surface of tungsten carbide. The experimental results showed that the two-axis UV polishing could polish 
the aspheric surface roughness of a tungsten carbide mold to $\mathrm{Rz} 8 \mathrm{~nm}$. Liang et al. [10] used single diamond abrasive grains to perform elliptical UV grinding on monocrystal sapphires in order to study the mechanism in a brittle-ductile transition zone during removal of materials. The contents of Liang et al.s research include the impact of a voltage phase difference, which could change the UV, on the critical depth of material removal. The research results of Liang et al. show that during machining at high vibration amplitude, material removal was carried out using ductile mode grinding. This research paper also proves that UV grinding can effectively perform ductile mode machining of hard and brittle materials. Xu et al. [11] carried out ultrasonic flexural vibration-assisted (UVFV) CMP on sapphire substrate. Xu et al. compared the machining features of the material removal rate and polished surface morphology between traditional CMP and UFV-CMP under different pressures. Xu et al's research results show that the surface roughness of polished sapphire substrate, as measured by atomic force microscopy (AFM) of UFV-CMP, was $0.83 \AA$, far more improved than the traditional CMP's $2.12 \AA$ A. Besides, UFV-CMP could tremendously enhance the material removal rate on sapphire substrate.

UV drilling, cutting and abrasive machining can substantially increase the material removal rate, decrease the cutting force, reduce tool wear and improve surface finishing. In Tsai and Yang's research paper [12], UV-CMP and UV traditional diamond disk polishing were employed to carry out a series of in-depth polishing studies on copper substrate. It was found that the material removal rate with UV-CMP was 50-90\% greater than CMP, and the material removal rate with UV traditional diamond disk polishing was double that of traditional diamond disk polishing. The research also showed that the addition of UV could improve the surface roughness of copper substrate and tremendously reduce torque force. Wang et al's paper [13] studied the UV grinding of hard and brittle materials. Through simulation and experiment, Wang et al. proved that UV grinding of hard and brittle materials could not only reduce grinding force, but also improve the workpiece's surface quality. Liang et al. [14] used a two-dimensional UV grinding method to conduct monocrystal silicon machining. The research results showed that axial UV grinding could greatly improve the workpiece's surface quality and obviously reduce the grinding force. During vertical UV grinding, although the grinding force could be obviously reduced, the surface roughness increased slightly. Liang et al. used a resin-bonded diamond wheel to perform elliptical UV grinding on monocrystal sapphire and conducted a series of grinding studies on the wear mechanism. The research contents included machining in the presence or absence of UV grinding and a comparison of the surface roughness and wheel surface of a workpiece for these two machining techniques. The research results of Liang et al.s study [15] showed that the UV grinding wheel could continue sharp diamond-cutting for a longer period of time. This method could also reduce the grinding force and force ratio $(\mathrm{Fn} / \mathrm{Ft})$, and produce a smoother workpiece surface. Currently, UV can also be applied to micro-electrical discharge machining (micro-EDM). When applied to microEDM drilling, UV can enhance the precision drilling of micro-holes and improve surface roughness. Ichikawa and Natsu [16] applied UV to machining fluid during micro-EDM machining in order to achieve debris removal. Ichikawa and Natsu's research results indicated that after adding UV in the micro-EDM process, the machining speed could be greatly increased, and the wear ratio of the tool electrode could be reduced. However, the above studies only applied UV as an auxiliary combining power, and its combining intensity was very weak, leading to easier ablation of abrasive grains in the polishing process, and resulting in a loss of grinding action. In most of the research literature, the workpiece to be machined was soaked in polishing fluid. Nevertheless, using a large amount of polishing fluid is a waste of material, and the machining time was still very long.

The objective of this study is to make use of parenchyma cells of porous bamboo charcoal to transmit grinding slurry from a vascular bundle to the end of the bamboo charcoal, and to apply UV to the polishing process of silicon chips. When a specimen's surface is being polished, the parenchyma cells at the end of the bamboo charcoal will exert a grasping force. In this way, the abrasive grains between the bamboo charcoal and workpiece are not so easily ablated. Besides, when a workpiece surface is machined in polishing fluid, the impact of friction heat can be reduced, effectively improving the burning marks on the workpiece's surface. After abrasive grains are ablated from the polishing end of bamboo charcoal, they return to the polishing fluid and are again transmitted to the parenchyma cells at the end of the bamboo charcoal to repeat the polishing action. The polishing end of bamboo charcoal continuously regenerates, improving the surface roughness of a workpiece in a very short period of time.

\section{Experimental Devices and Methods}

2.1. UV Polishing Equipment. The UV polishing system used in this study (Multi LAP, ML-35 M, Taga Electric Co., Japan) was installed in a single lapping machine (M-15FS, Jeng Yueh Enterprise Co., Taiwan). It was attached to a self-made speed-changing spindle motor system and pressure output equipment to conduct a grinding and polishing test. The experimental devices are shown in Figure 1.

For machining, bamboo charcoal was installed in the polishing spindle. Polishing fluid was injected through the pressure tank to the vascular bundle inside the bamboo charcoal. UV polishing was carried out using a spindle and turning platen. During polishing, the silicon wafer was fixed to the polishing disk, and UV devices were applied onto the upper end of the bamboo charcoal. Polishing of the silicon wafer was performed via UV action.

2.2. Materials Used in the Experiments. The bamboo charcoal used in this experiment was Moso bamboo carbonized under a temperature of $1000^{\circ} \mathrm{C}$. Its density was around $0.6 \mathrm{~g} / \mathrm{cm} 3$, its specific surface area was $300 \mathrm{~m} 2 / \mathrm{g}$ and its carbon content was $75 \sim 86 \%$. The bamboo charcoal's structure is shown in Figure 2. The specimen used in the experiment was an Ntype silicon wafer with a thickness of $610-640 \mu \mathrm{m}$, an electric resistance of 2-7 $\Omega-\mathrm{cm}$ and an $\mathrm{Ra}$ of $0.252 \mu \mathrm{m}$. 


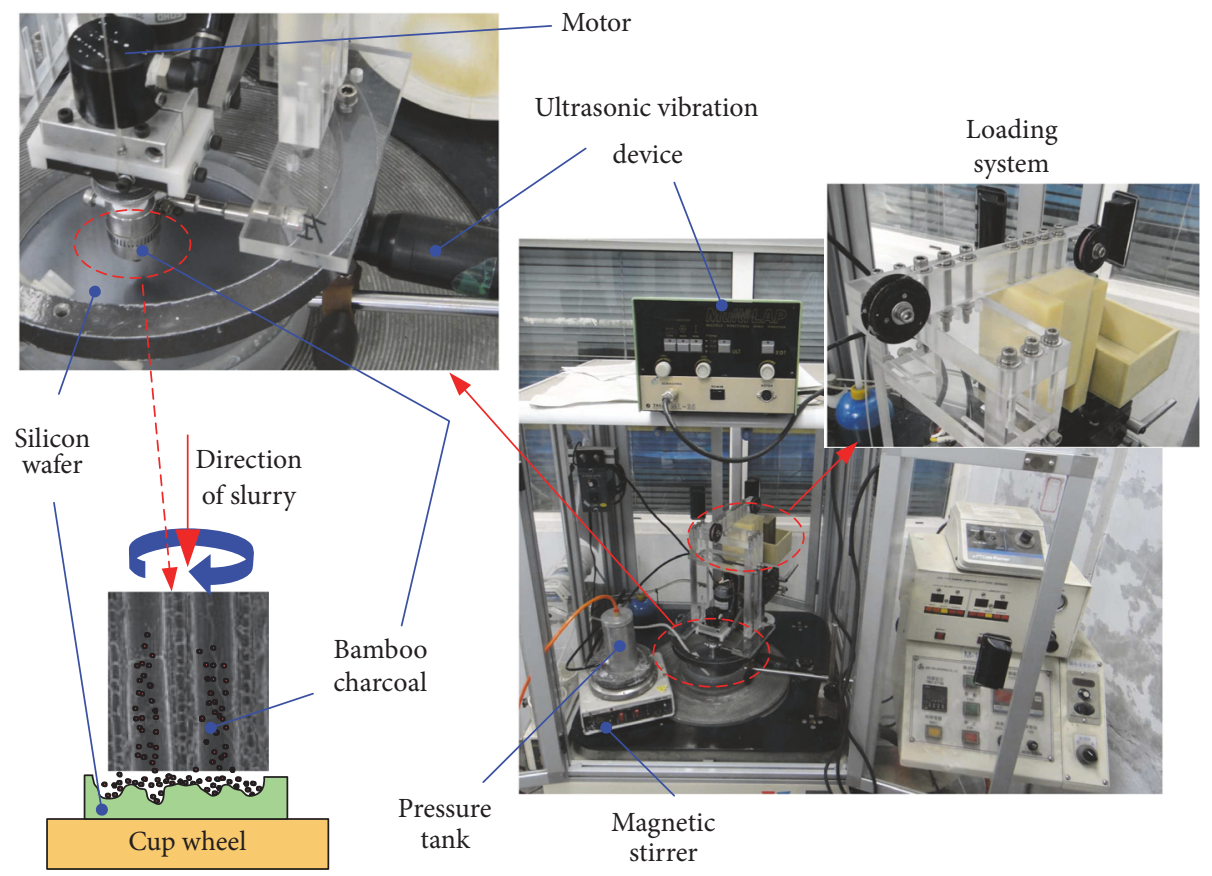

FIgURE 1: Experimental devices.

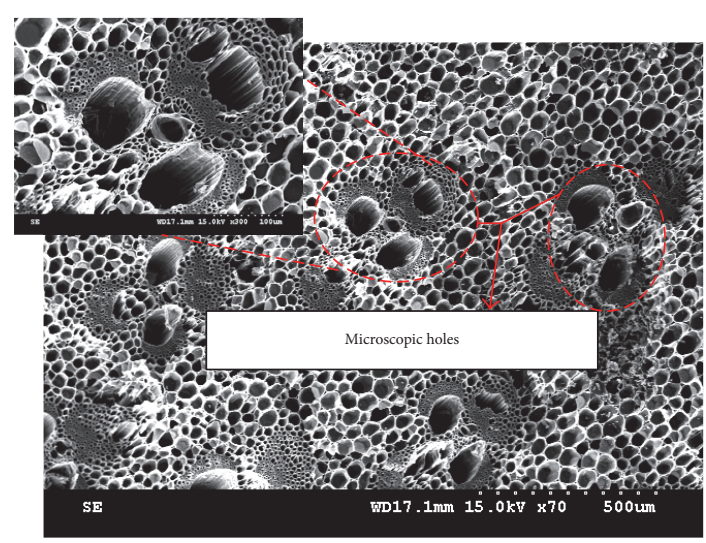

Figure 2: SEM image of bamboo charcoal structure.

2.3. Methodology. First of all, bamboo charcoal was cut into the required size and placed into an ultrasonic oscillator for cleaning for $30 \mathrm{~min}$, with the purpose of removing debris in the cutting process. After cleaning, it was taken out for drying. All the silicon wafer specimens had their oil cleaned, and their surface roughness was then measured. After the specimens were polished under different UV parameters, surface profilometry (E-35A, Tokyo Seimitsu Co., Japan) was used again to measure surface roughness 5 times at different positions for each specimen, and a mean was finally obtained. As for the study and observation of surface morphology, a scanning electron microscope (SEM) (TESCAN VEGA TS. 5136LS, Tescan, Brno, Czech Republic) and an atomic force microscope (AFM) (D3100, Veeco Instruments Inc., NY, USA) were used. Fixed parameters of the experiment are shown in Table 1 , and the related parameters for machining are shown in Table 2.
TABLE 1: The constant parameters of UV polishing.

\begin{tabular}{lc}
\hline Parameters & Description \\
\hline Polishing tools $(\mathrm{mm})$ & Bamboo charcoal $(8 * 8 * 20)$ \\
Specimen & Silicon wafer \\
Particle Grain Size $(\mu \mathrm{m})$ & Diamond powder 2-4 \\
Solution & Pure Water \\
Platen speed $(\mathrm{rpm})$ & 40 \\
Vibration amplitude $(\mu \mathrm{m})$ & 5 \\
\hline
\end{tabular}

TABLE 2: The variable parameters of UV polishing varied.

\begin{tabular}{lc}
\hline Parameters & Description \\
\hline Vibration frequency $(\mathrm{KHz})$ & $24,26,28,30,32$ \\
Polishing time (min) & $5,10,15,20,25$ \\
Spindle speed (rpm) & $600,900,1200,1500$ \\
Concentration (wt\%) & $0.1,0.3,0.5$ \\
Loading (N) & $15,25,35$ \\
\hline
\end{tabular}

\section{Results and Discussion}

This study adopted a single lapping machine together with a self-made frequency-changing, speed-adjustable bamboo charcoal polishing spindle and UV devices. This experiment used diamond slurry to conduct polishing tests on monocrystal silicon wafers. This was a single factor experiment using machining parameters, including: UV frequency, polishing time, spindle speed, polishing fluid concentration, axial load and specimen surface morphology. It mainly explored the impacts of different machining conditions on the polishing of silicon wafer specimens, and the performance of surface 


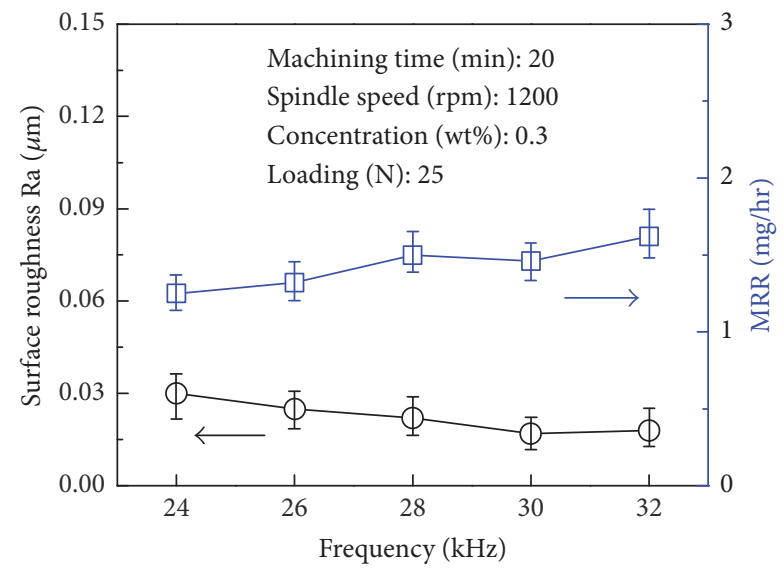

FIGURE 3: Impacts of vibration frequency on surface roughness.

roughness and the material removal rate were observed. The experimental results were obtained as follows.

3.1. Impacts of UV Frequency on Surface Roughness. Figure 3 shows the impact of UV frequency on surface roughness. As observed in the figure, when the machining frequency increased from $24 \mathrm{kHz}$ to $32 \mathrm{kHz}$, the surface roughness value $\mathrm{Ra}$ was in the range of $0.03 \mu \mathrm{m} \sim 0.017 \mu \mathrm{m}$ for a machining time of $20 \mathrm{~min}$. When the machining frequency was $30 \mathrm{kHz}$, a more obvious effect was found on the surface roughness of the specimen.

This information proves that it is easier to achieve better polishing effects under UV conditions mainly because diamond grains can go through a vascular bundle of bamboo charcoal faster due to the UV effect. Meanwhile, a selfsharpening action works continuously at the end of the bamboo charcoal. As a result, the specimen surface is ground by a larger amount of diamond abrasive grains during polishing and machining, thereby increasing the material removal rate, enhancing the polishing efficiency and achieving a better surface roughness within a short period of time. As for the bamboo charcoal polishing process in the absence of UV, since grinding and polishing can be carried out only by the diamond abrasive grains being transmitted out of the vascular bundle, the grinding is insufficient. The polishing efficiency is poor, making it impossible to achieve a better surface roughness within a short period of time.

On the other hand, after observing the impact of the UV frequency on the material removal rate, as shown in Figure 3, we clearly found that with an increase in vibration frequency, the material removal rate increased because the UV effect made the diamond slurry go through the vascular bundle of bamboo charcoal more quickly, and further enhancing the removal rate of machining materials. When the vibration frequency reached $32 \mathrm{kHz}$, although the material removal rate continued to increase, the surface roughness did not improve. The reason is that the increase in vibration frequency led to wear on the abrasive end of the bamboo charcoal and has prevented the surface roughness from being continuously improved.

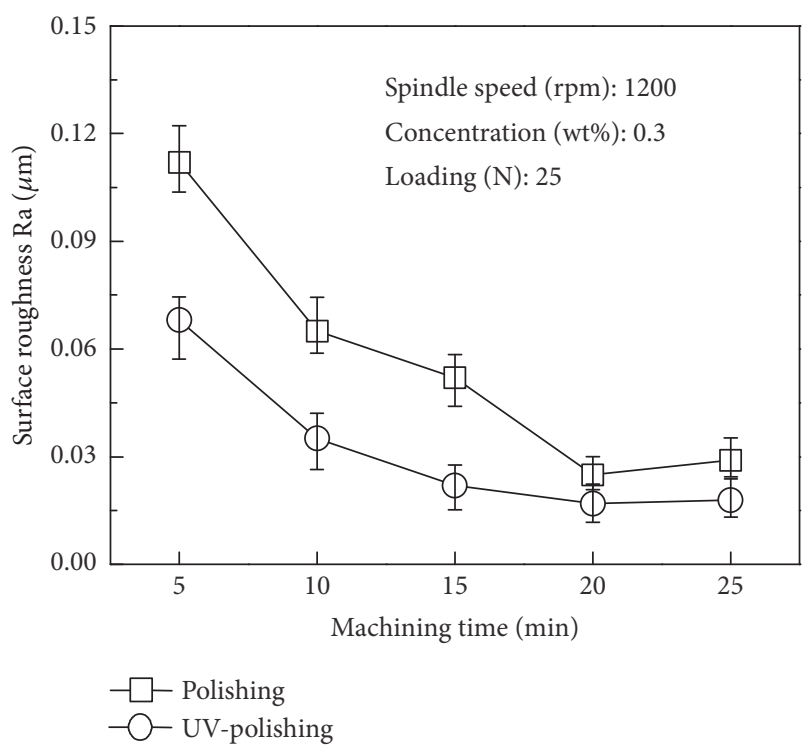

FIGURE 4: Impacts of polishing time on surface roughness.

3.2. Impact of Polishing Time on Surface Roughness. Figure 4 shows how traditional polishing and UV polishing affect the surface roughness after different lengths of machining time. As observed in the figure, with increased machining time, the two ways of machining exhibit declining performances regarding surface roughness on silicon wafers. When making comparisons of the surface roughness affected by the two ways of machining in terms of the machining time, UV polishing obviously had less impact on the surface roughness compared to traditional polishing.

When further analysis and observations were made, it was found that after UV polishing for $15 \mathrm{~min}$, we could achieve the same surface roughness as that of traditional polishing for $20 \mathrm{~min}$. Through UV machining, the material removal rate could be improved, and the machining time further shortened. When UV polishing time was conducted for $20 \mathrm{~min}$, an optimal improvement effect was achieved; the surface roughness fell from the original $\mathrm{Ra}$ of $0.252 \mu \mathrm{m}$ to an $\mathrm{Ra}$ of $0.017 \mu \mathrm{m}$, showing an improvement rate of $93 \%$. If the polishing time would continue to increase, the surface roughness would remain the same and unnecessary consumption of bamboo charcoal and abrasive grains would increase, resulting in decreased efficiency and increased costs.

3.3. Impact of Spindle Speed on Surface Roughness. Figure 5 shows the impact of different spindle speeds on surface roughness. We can clearly observe the impact of the two different ways of machining on the surface roughness of the specimen. There appears to be a trend where the surface roughness for both ways declines with the rise in spindle speed since speed is a very important parameter affecting the polishing effect; the faster the speed, the longer the machining path. This implies that the specimen's surface is polished more times within the unit time, and the polishing density is higher.

On the other hand, under UV polishing, the surface roughness obviously improves with the increased speed. For the cause of this phenomenon, it is speculated that during 


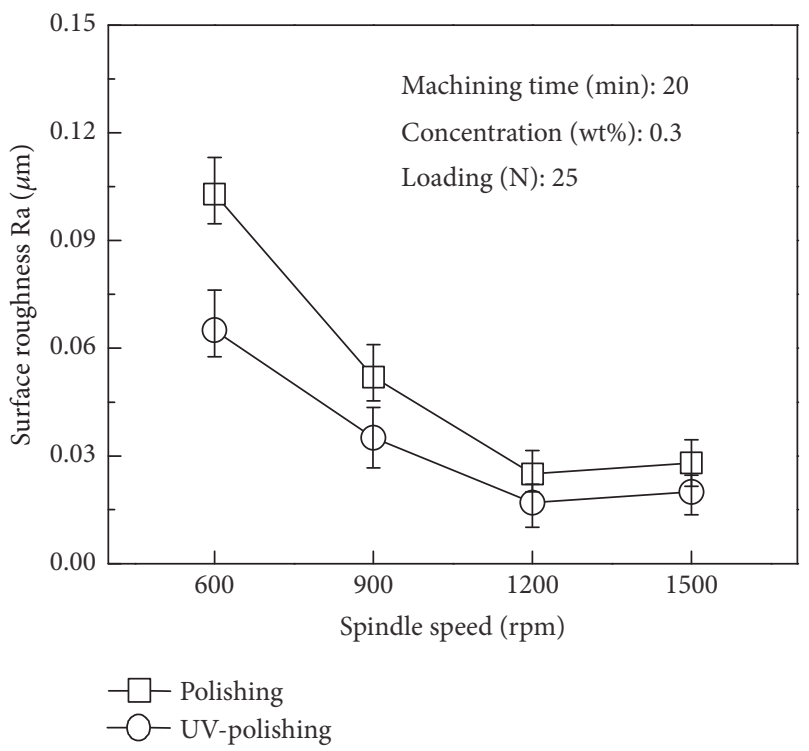

FIGURE 5: Impacts of spindle speed on surface roughness.

UV polishing, the ground slurry evenly flows out from the vascular bundle of bamboo charcoal, improving the surface roughness of the wafer. Nevertheless, when the spindle speed rises to $1500 \mathrm{rpm}$, abrasive grains are easily ablated due to centrifugal force; as a result, the surface roughness of the wafer does not show any significant improvement.

3.4. Impact of Concentration on Surface Roughness. Figure 6 shows the impact of different concentrations of polishing fluids on surface roughness. As clearly observed in the figure, when machining uses a polishing fluid with a concentration of $0.3 \mathrm{wt} \%$, the silicon wafer has better surface roughness. These results show that when the concentration of diamond powder polishing fluid is $0.1 \mathrm{wt} \%$, such a low concentration creates an insufficient grinding effect; however, when the concentration is over $0.5 \mathrm{wt} \%$, such a high concentration can easily cause abrasive grains to accumulate and block the vascular bundle. The polishing fluid then cannot pass through smoothly, and the self-sharpening and grinding abilities of the bamboo charcoal and abrasive grains are reduced, making it impossible to achieve an improvement in surface roughness.

After further observation and analysis, the surface roughness value produced from UV polishing is still lower than that of traditional polishing. Because of the UV action, the diamond powder polishing fluid flows out of the vascular bundle of bamboo charcoal more easily, so that better surface roughness can be obtained.

3.5. Impact of Loading on Surface Roughness. Figure 7 shows the relationship between machining loading and surface roughness. We observe from the figure that when a loading of $25 \mathrm{~N}$ is applied during traditional polishing, a better surface roughness can be achieved. However, for UV polishing with different loadings applied, surface roughness values are all lower than those from traditional polishing. Besides, due to

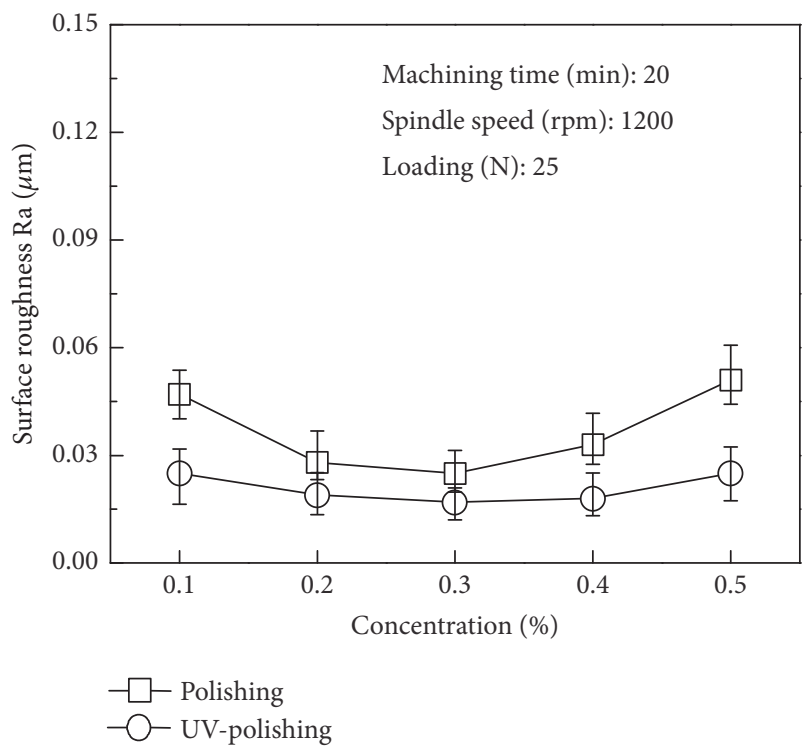

FIGURE 6: Impacts of concentration on surface roughness.

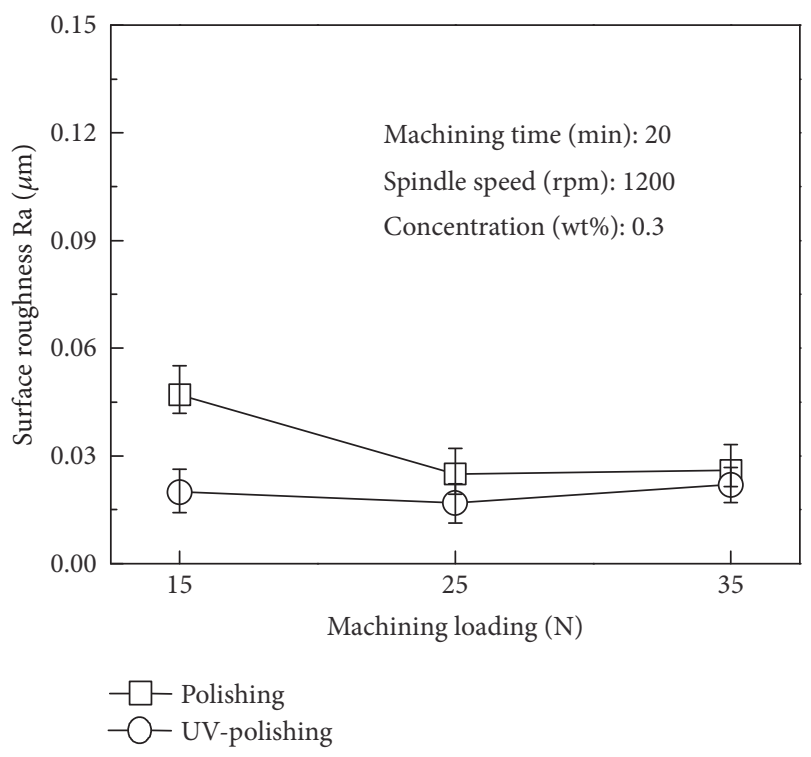

FIGURE 7: Impacts of loading on surface roughness.

the assistance of ultrasound for polishing, surface roughness values do not show much change under different loadings.

To determine the impact of different loadings on surface roughness, further observations were made, as shown in Figure 7 . When a loading of $25 \mathrm{~N}$ was applied for different lengths of machining time, better surface roughness resulted. When the loading was increased to $35 \mathrm{~N}$, the surface roughness rose. The reason for this is that when loading is excessive, chipping occurs at the abrasive end of the bamboo charcoal, leading to an uneven contact face with the silicon wafer and increasing the surface roughness. From this we know that excessive loading does not improve the polishing project.

3.6. Observation of Surface Morphology. Figure 8 shows the SEM, AFM and measured surface roughness photographs 

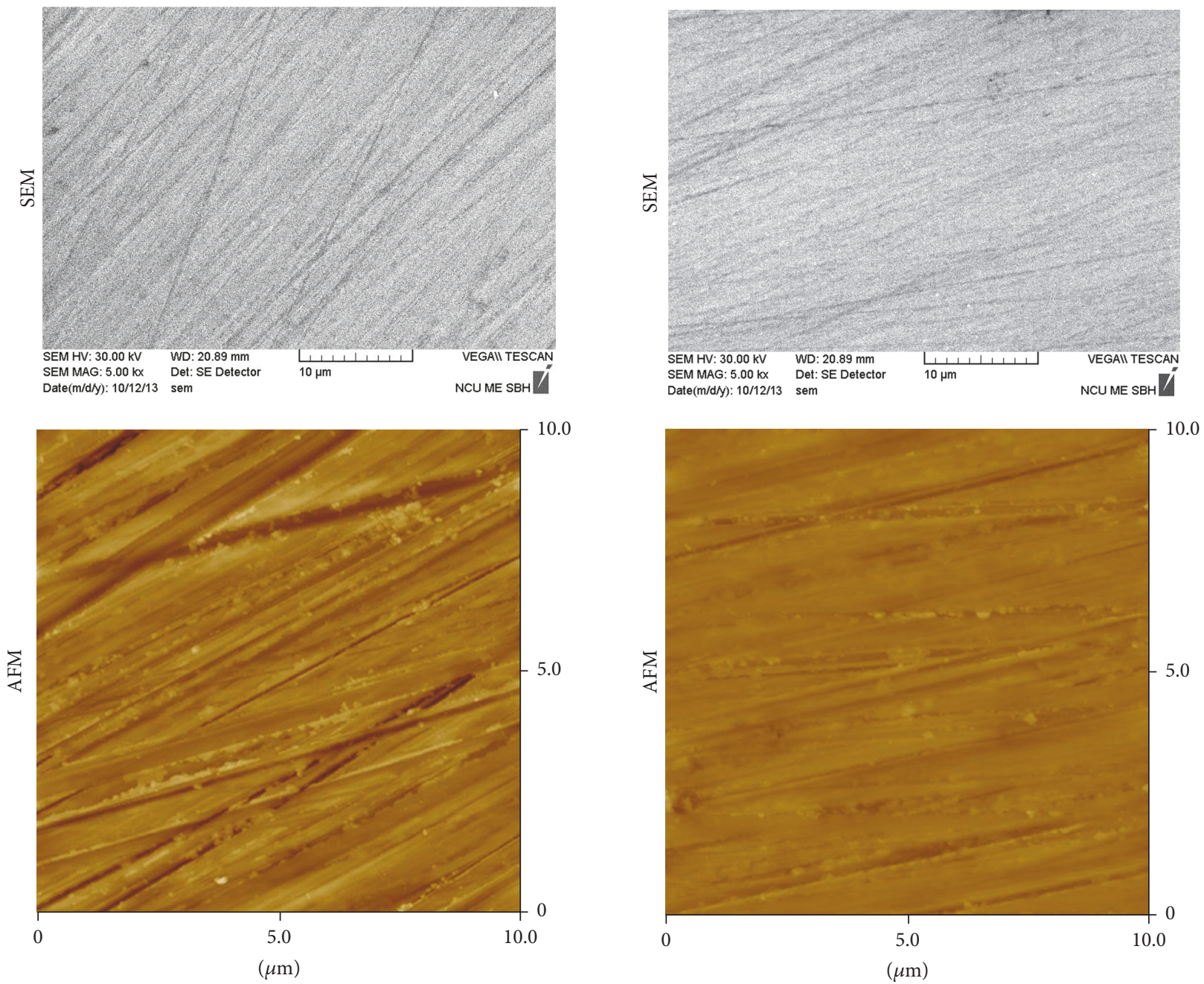

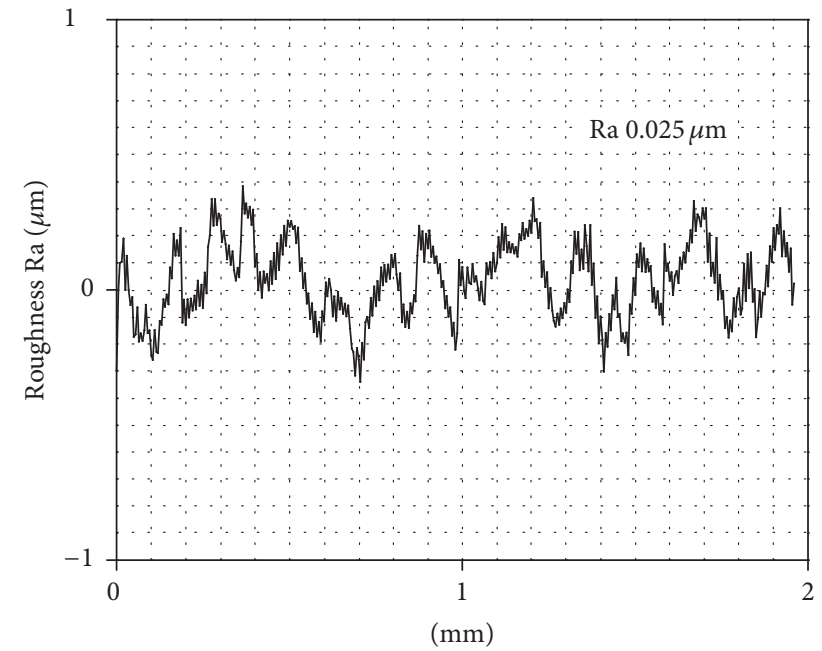

(a)

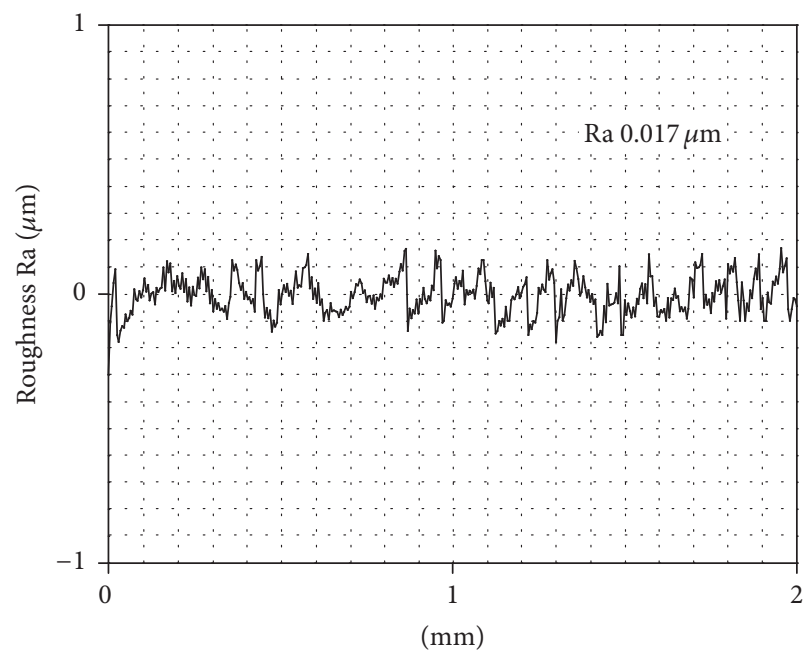

(b)

FIGURE 8: Comparison of polished specimen after (a) bamboo charcoal polishing (b) UV bamboo charcoal polishing. 
of specimen surfaces after the two polishing methods were employed. The machining conditions were a machining time of $20 \mathrm{~min}$, a spindle speed of $1200 \mathrm{rpm}$, a loading of $25 \mathrm{~N}$ and diamond polishing fluid at a concentration of $0.3 \%$. From the bamboo charcoal polishing method shown in Figure 8(a), one can observe more obvious scratching on the specimen surface, while the surface roughness $\mathrm{Ra}$ is $0.025 \mu \mathrm{m}$. From the UV bamboo charcoal polishing method shown in Figure 8(b), one can see that the scratches on the silicon wafer's surface are gradually ground off, and a flatter surface appears, with a surface roughness $\mathrm{Ra}$ of $0.017 \mu \mathrm{m}$.

\section{Conclusions}

This study used UV bamboo charcoal to polish the surface of silicon wafer workpieces, greatly improving the surface quality of the specimen within a shorter period of time. According to the experimental results, the following conclusions are drawn:

(1) Suitable UV machining parameters are: a vibration frequency of $30 \mathrm{kHz}$, a diamond polishing fluid concentration of $0.3 \%$, a polishing time of $20 \mathrm{~min}$, machining loading of $25 \mathrm{~N}$ on the workpiece surface, and a spindle speed of $1200 \mathrm{rpm}$.

(2) When axial loading increases to $35 \mathrm{~N}$, the loading is excessively high, and scratches are easily produced on the specimen's surface, leading to an increase in surface roughness.

(3) Suitable machining parameters should be set in UV polishing experiments with silicon wafer specimens because the original surface roughness $\mathrm{Ra}$ of $0.252 \mu \mathrm{m}$ can be reduced to become a mirror-like surface with an $\mathrm{Ra}$ at $0.017 \mu \mathrm{m}$ after $20 \mathrm{~min}$.

\section{Conflicts of Interest}

The authors declare that they have no conflicts of interest.

\section{References}

[1] J. Zhu, J. Jia, F. L. Kwong, D. H. L. Ng, and S. C. Tjong, "Synthesis of multiwalled carbon nanotubes from bamboo charcoal and the roles of minerals on their growth," Biomass and Bioenergy, vol. 36, pp. 12-19, 2012.

[2] X. Li, B. Lei, Z. Lin, L. Huang, S. Tan, and X. Cai, “The utilization of bamboo charcoal enhances wood plastic composites with excellent mechanical and thermal properties," Materials and Design, vol. 53, pp. 419-424, 2014.

[3] M.-Y. Tsai, "Polycrystalline diamond shaving conditioner for CMP pad conditioning," Journal of Materials Processing Technology, vol. 210, no. 9, pp. 1095-1102, 2010.

[4] T. Doi, I. D. Marinescu, and S. Kurokawa, "Chapter 7 Summary-The Future of CMP/Polishing Technologies," in Advances in CMP Polishing Technologies, pp. 305-308, 2012.

[5] M.-Y. Tsai, S.-T. Chen, Y.-S. Liao, and J. Sung, "Novel diamond conditioner dressing characteristics of CMP polishing pad," International Journal of Machine Tools and Manufacture, vol. 49, no. 9, pp. 722-729, 2009.
[6] L. C. Zhang, A. Q. Biddut, and Y. M. Ali, "Dependence of pad performance on its texture in polishing mono-crystalline silicon wafers," International Journal of Mechanical Sciences, vol. 52, no. 5, pp. 657-662, 2010.

[7] O. Kirino and T. Enomoto, "Ultra-flat and ultra-smooth $\mathrm{Cu}$ surfaces produced by abrasive-free chemical-mechanical planarization/polishing using vacuum ultraviolet light," Precision Engineering, vol. 35, no. 4, pp. 669-676, 2011.

[8] Y. Li, Y. Wu, L. Zhou, and M. Fujimoto, "Vibration-assisted dry polishing of fused silica using a fixed-abrasive polisher," International Journal of Machine Tools and Manufacture, vol. 77, pp. 93-102, 2014.

[9] H. Suzuki, S. Hamada, T. Okino, M. Kondo, Y. Yamagata, and T. Higuchi, "Ultraprecision finishing of micro-aspheric surface by ultrasonic two-axis vibration assisted polishing," CIRP Annals Manufacturing Technology, vol. 59, no. 1, pp. 347-350, 2010.

[10] Z. Liang, X. Wang, Y. Wu, L. Xie, L. Jiao, and W. Zhao, "Experimental study on brittle-ductile transition in elliptical ultrasonic assisted grinding (EUAG) of monocrystal sapphire using single diamond abrasive grain," International Journal of Machine Tools and Manufacture, vol. 71, pp. 41-51, 2013.

[11] W. Xu, X. Lu, G. Pan, Y. Lei, and J. Luo, "Ultrasonic flexural vibration assisted chemical mechanical polishing for sapphire substrate," Applied Surface Science, vol. 256, no. 12, pp. 39363940, 2010.

[12] M.-Y. Tsai and W.-Z. Yang, "Combined ultrasonic vibration and chemical mechanical polishing of copper substrates," International Journal of Machine Tools and Manufacture, vol. 53, no. 1, pp. 69-76, 2012.

[13] Y. Wang, B. Lin, S. Wang, and X. Cao, "Study on the system matching of ultrasonic vibration assisted grinding for hard and brittle materials processing," International Journal of Machine Tools and Manufacture, vol. 77, pp. 66-73, 2014.

[14] Z. Liang, Y. Wu, X. Wang, and W. Zhao, "A new twodimensional ultrasonic assisted grinding (2D-UAG) method and its fundamental performance in monocrystal silicon machining," International Journal of Machine Tools and Manufacture, vol. 50, no. 8, pp. 728-736, 2010.

[15] Z. Liang, X. Wang, Y. Wu, L. Xie, Z. Liu, and W. Zhao, "An investigation on wear mechanism of resin-bonded diamond wheel in Elliptical Ultrasonic Assisted Grinding (EUAG) of monocrystal sapphire," Journal of Materials Processing Technology, vol. 212, no. 4, pp. 868-876, 2012.

[16] T. Ichikawa and W. Natsu, "Realization of micro-EDM under ultra-small discharge energy by applying ultrasonic vibration to machining fluid," in Proceedings of the 17th CIRP Conference on Electro Physical and Chemical Machining, ISEM 2013, pp. 326331, bel, April 2013. 

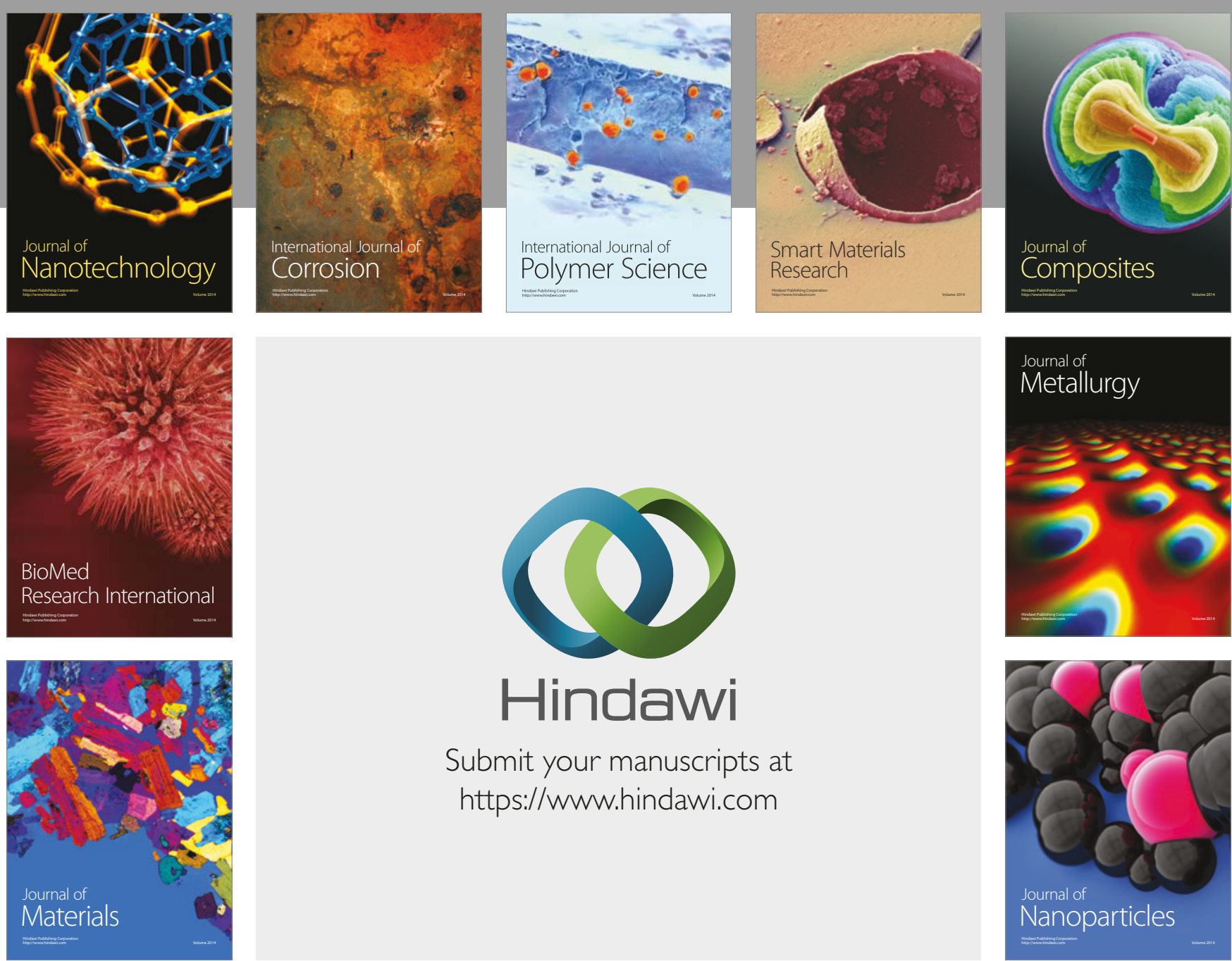

\section{Hindawi}

Submit your manuscripts at

https://www.hindawi.com
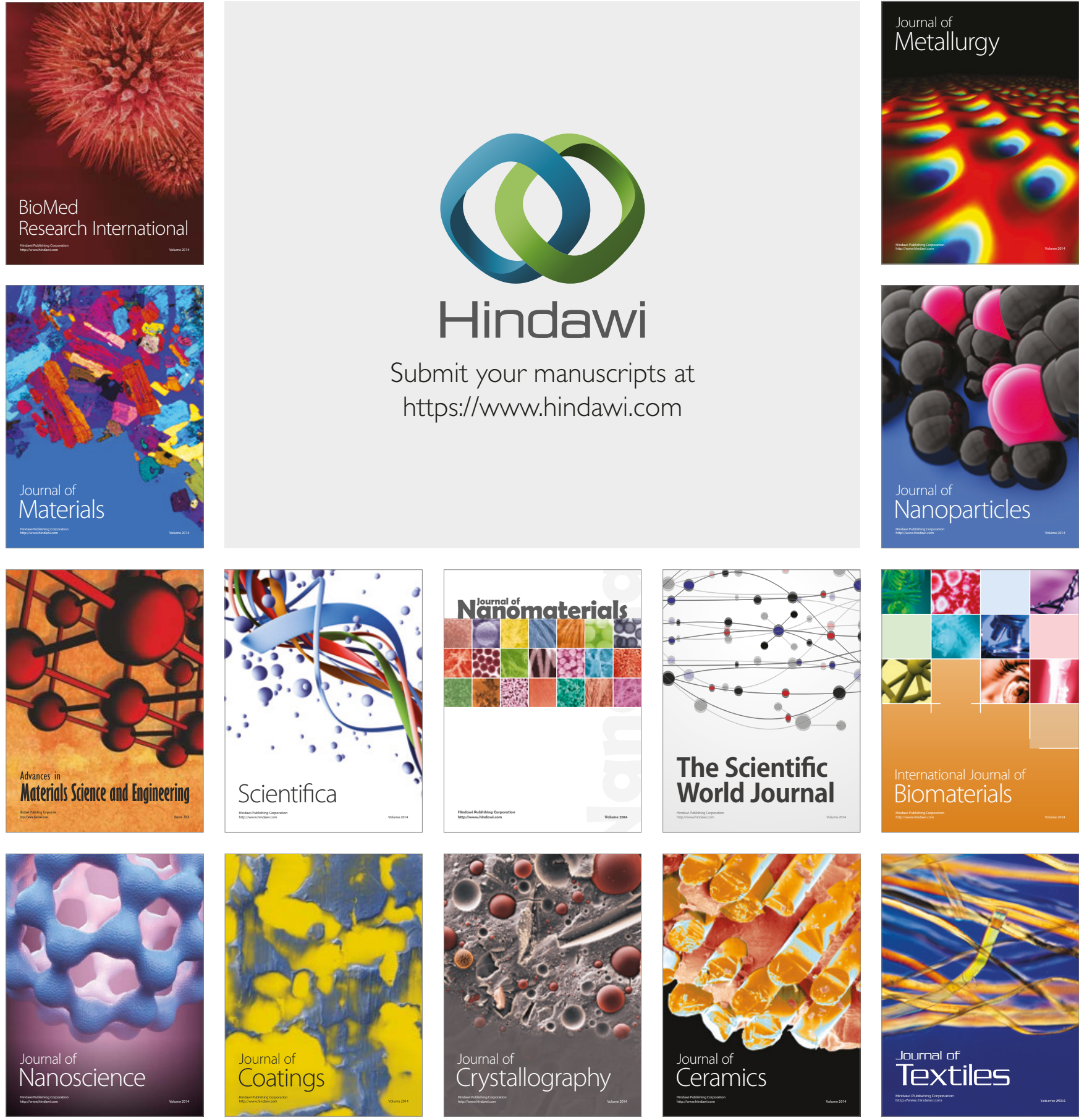

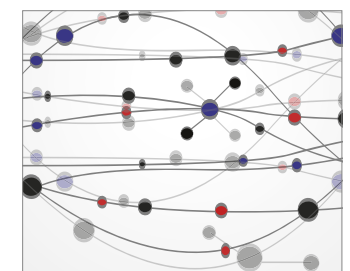

The Scientific World Journal
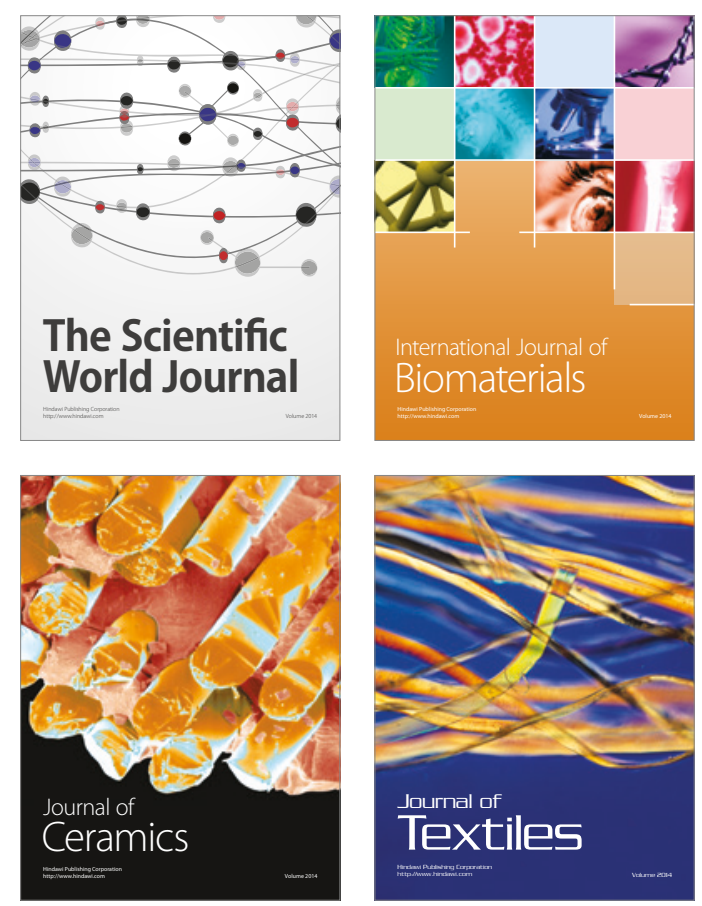